\title{
The Benefits of Staffing and Paying More: The Effects of Staffing Levels and Wage Practices for Registered Nurses on Hospitals' Average Length of Stay
}

\author{
Mark P. Brown, Michael C. Sturman, and Marcia J. Simmering
}

\begin{abstract}
With health care costs rising, increased attention has been paid to the human resource practices of hospitals. This chapter examines the effects that staffing levels and wages of registered nurses have on hospitals' average lengths of stay. Based on data from 352 California hospitals, we show that both increased staffing levels and wage rates relate to decreased average lengths of stay. Furthermore, based on our most complete and accurate models, it appears that wage may be more effective for improving the average lengths of stay than would increasing the quantity of RNs. The results of this chapter have a number of implications for human resource practices of RNs and for future research on health care management practices.
\end{abstract}

\section{Introduction}

The precipitous rise in health care costs over the past 20 years has been well documented. Among the factors that contribute to increases in health care costs, those associated with providing hospital care have received considerable attention (Carey, 2000). Numerous factors are believed to contribute to hospitals' costs (e .g. patient case mix, physician practice patterns, etc.). Particular attention by both health care managers and the public has been focused on the impact of hospital's labor expenses on their costs, and thus health care costs in general. Moreover, since labor costs represent over $50 \%$ of hospitals' total costs, they are of marked importance in understanding the rapid rise in health care costs (American Hospital Association, 1993; Langland-Orban, Gapenski \& Vogel, 1996).

Two important contributors to hospitals' labor costs are staffing levels and wage practices for registered nurses (RNs). Staffing levels and wage costs for RNs likely explain a substantial portion of hospitals' total labor expenses. Thus, staffing and compensation practices for RNs seem to be a 
particularly relevant area of investigation when considering healthcare costs (Melberg, 1997; Robertson, Dowd \& Hassan, 1997). Moreover, while RN labor costs have a significant economic effect, the services provided by these RNs affect important indicators of hospitals' operational effectiveness (Melberg, 1997; Robertson et al., 1997). Specifically, they may influence the efficiency of patient care through their influence on the quality of nursing care (Melberg, 1997; Robertson et al., 1997). While a positive relation between nursing practices and patient outcomes is largely accepted (e .g. Melberg, 1997), the relationship between RN staffing levels, wage practices, and patient outcomes remains less clear (Melberg, 1997; Robertson et al., 1997). While some evidence shows that hospitals hiring more RNs have better patient outcomes than those with fewer RNs (e.g. Needleman, Buerhaus, Mattke, Stewart \& Zelevinsky, 2001), only anecdotal evidence suggests paying RNs more will lead to better patient outcomes. Staffing levels for RNs affect outcomes by influencing the quantity and quality of care nurses render. Staffing related quality of care decreases have been attributed to numerous factors including the deleterious effect of deficient RN staffing levels on the incidence of nursing mistakes (Aiken, Clarke, Sloane, Sochalski et al., 2001). Prevailing arguments assert that RN wages influence patient outcomes by affecting the quality and quantity of RNs that can be hired and retained, and subsequently the quality of patient care (Melberg, 1997; Robertson et al., 1997).

While some attention has been devoted to understanding the relationship between RN staffing levels and hospitals' effectiveness, little empirical attention has been devoted to simultaneously considering the relationship between RN staffing levels. RN wage practices, and hospitals' effectiveness. Thus, because staffing and wage practices for RNs are important for clinical as well as economic reasons, this manuscript examines the effect of hospitals' staffing and wage levels for RNs on hospitals' operational effectiveness. We ask the following questions: (a) do hospitals that hire more RNs have better outcomes; (b) do hospitals that pay RNs more have better outcomes; and (c) what is the relative advantage of greater staffing vs. greater wages?

One important indicator of hospitals' operational effectiveness is their average length of stay (Melberg, 1997; Robertson et al., 1997). Average length of stay (ALOS) is the average time, measured in days, which patients stay in a particular hospital. ALOS has been used as a measure of performance in previous hospital research (e .g. Needleman et al., 2001; Phillips, 1999; Sear, 1992) and is often seen as an important measure of both treatment quality and efficiency (Thomas, Guire, \& Horvat, 1997). Typically, hospitals with shorter length of stay are considered to provide better and more efficient care, whereas hospitals with longer lengths of stays are presumed to provide lower quality less efficient care (Thomas et al., 1997). Because RNs provide much of the skilled care patients receive in hospitals, their 
performance has important implications for hospitals' level of care, efficiency, and thus their ALOS (Groshen \& Krueger, 1990; Melberg, 1997; Robertson et al., 1997; Thomas et al., 1997).

The research reported in this chapter should be useful in several arenas. For the public, it should be useful in clarifying arguments surrounding the impact of human resource practices on hospitals' clinical outcomes. Considerable media attention has been focused on working conditions in hospitals (Aiken et al., 2001). Among the most vocal of critics have been RNs (e.g. SEIU, 2002). Citing wage issues and insufficient staffing levels as paramount among a host of other concerns, RNs have emphasized the implications of these conditions for hospitals' patient care (e .g. SEIU, 2002). This chapter should give the public some direction regarding the validity of these concerns. For healthcare managers, the manuscript should be useful in clarifying the operational implications of pursuing particular staffing or wage strategies for RNs. In particular, since healthcare managers face competing demands to maintain economic efficiency while sustaining acceptable levels of care, this chapter should be useful in assessing the potential tradeoff between the pursuit of economic efficiency and the objective of providing high quality care.

\section{The Effect of Registered Nurses' Staffing Levels and Wages on Hospital Efficiency}

Past research has shown that a hospital's quantity of RNs is associated with greater hospital effectiveness (Needleman et al., 2001). The logic behind this, clearly, is that more nurses can provide more and better service to a set of patients. We expect to replicate this finding in this chapter, too. However, as of yet not addressed, is the extent to which greater pay for the same number of nurses may be associated with greater hospital efficiency.

Efficiency wage theory suggests three explanations for the positive effects of hospitals' RN wage practices on ALOS. According to the principles of efficiency wage theory, higher wages will: (a) help recruit better qualified and more capable RNs; (b) cause present RNs to be more efficient ; and (c) engender in RNs a sense of obligation to the hospital, which makes them more efficient.

High RN wages should improve employee and organizational efficiency because hospitals that offer high relative wages can attract and retain highly qualified job candidates (Akerlof \& Yellen, 1986; Campbell, 1993; Yellen, 1984; Weiss, 1988). Higher wages also generate larger applicant pools that allow hospitals to be more selective when hiring (Bordeau \& Rynes, 1985; Raff \& Summers, 1987; Williams \& Dreher, 1992). Because hospitals that pay more for RNs should be able to hire and retain the most capable applicants (i.e. RNs who are the most efficient and provide the best care), hospitals that pay higher wages should experience both quality of care and efficiency increases (Becker \& Huselid, 1998; 
Bordreau \& Rynes, 1985; Campbell, 1993; Hunter \& Hunter, 1984; Williams \& Dreher, 1992). Thus, the ability to attract and retain more qualified RNs, due to high relative wages, will decrease (i.e. improve) hospitals' ALOS.

Efficiency wage theory also suggests that higher wages improve employee and organizational efficiency by decreasing employees' unproductive or shirking behavior (Akerlof \& Yellen, 1984; Milkovich \& Newman, 2002). These effects may be particularly important when employees' job performance is costly and/or difficult to monitor, which is likely the case with some RNs' positions (Capelli \& Chauvin, 1991; Rebitzer \& Taylor, 1995; Walsh, 1999). Indeed, when wages are high, employees who shirk may suffer personal economic costs from involuntary turnover (Akerlof \& Yellen. 1984; Capelli \& Chauvin, 1991). Thus, RNs in hospitals with higher wages may be more efficient and provide higher quality patient care, because, if they lose their job, they may be unable to find similarly high-paying positions.

Norm-gift exchange models provide another efficiency wage theory-based explanation for the positive effects of RN wages on hospitals' ALOS (Akerlof, 1982; Gerhart \& Milkovich, 1992). Norm-gift exchange models assert that, as a consequence of employee-firm exchanges, employees acquire sentiments for their firms and feel obliged to maintain equity in these exchanges (Akerlof, 1982; Cropanzano \& Greenberg, 1997; Gerhart \& Milkovich, 1992; Yellen 1984). Therefore, when inequity occurs in these exchanges, employees seek to return the relationship to a state of equity (Adams, 1963; Akerlof, 1982; Cropanzano \& Greenburg, 1997; Festinger, 1954; Gerhart \& Milkovich, 1992; Yellen, 1984). Accordingly, one explanation for the positive influence of greater pay for employees is that it creates a disequilibrium in the employee-firm relationship resulting in increases in employee effort and efficiency (Adams, 1963; Akerlof, 1982; Copanzano \& Greenberg, 1997; Festinger, 1954; Gerhart \& Milkovich, 1992; Akerlof, 1982). Yellen (1984) describes this as firms paying "workers a gift of wages in excess of the minimum required, in return for [workers'] gift of effort above the minimum required" ( $p$. 204). Thus, RNs in hospitals paying higher wages may make a concerted effort to perform effectively to reward their employing hospitals. This extra effort by these RNs will improve these hospitals' efficiency and quality of care (i.e. decrease ALOS).

To summarize, the quantity and quality of RNs in a hospital should improve the efficiency and quality of patient care. Increases in RNs' efficiency and quality of patient care should increase hospitals' efficiency, thus lowering their ALOS. Like previous research has shown (e.g. Needleman et al., 2001), we expect this can be achieved by staffing more RNs. We also argue above that this can be achieved by providing greater pay for RNs. Thus, we predict that hospitals with greater wages will have lower (i.e. better) ALOS. We will test this hypothesis below. 


\section{METHOD}

Sample

The sample for this research is 352 short-term stay acute care general hospitals in the state of California. Short-term stay hospitals are defined as those facilities with average lengths of stay less than thirty days (OSHPD, 1991). Acute care general hospitals are those hospitals that provide a comprehensive range of services as opposed to those hospitals that provide only specialized services such as a psychiatric care (MacEachern, 1962). Data is drawn from state mandated (i.e. Chapter 1326, California statuses of 1984) annual hospital disclosure reports provided by hospitals to the California Office of Statewide Health Planning and Development (OSHPD). Annual reports from 1996 to 1999 are used in this research.

\section{Dependent Measure}

ALOS is calculated by dividing a hospital's total number of patient days by their total discharges (OSHPD, 1991). Lower ALOS is indicative of organizational efficiency. Furthermore, some research suggests that ALOS may be a more appropriate indicator of hospitals' treatment quality than other indicators of hospitals' treatment quality (e.g. their mortality rates and their risk adjusted early readmission rates) (Thomas, 1996; Thomas et al., 1997 ; Thomas \& Hofer, 1998; Thomas \& Hofer, 1999) . Poor quality care is associated with higher ALOS because quality of care failures lead to greater patient complications, which in turn lead to higher lengths of stay (Thomas et al., 1997).

\section{Independent Measure}

The primary variables of interest in this study are the staffing and wage levels for RNs. Staffing levels were calculated by taking the total number of hours worked by RNs in each hospital. The mean RN hours in our samples of hospitals was 352,712 (median $=229,327 ;$ SD $=352,202$ ). This is roughly equivalent to 170 full time equivalents (assuming one full time equivalent works 2080 hours per year). Because the hours worked variable was heavily skewed, we used the logarithm of its value for subsequent analyses to make the variable better approximate a normal distribution and thus better meet the assumptions of our analytic methods.

Average wage levels were reported by each hospital in our sample. The mean RN hourly wage was $\$ 25.48$ (median $=\$ 24.99 ; S D=3.90)$. The distribution of wage levels were approximately normal, so no transformation of the data was necessary. 


\section{Control Variables}

We controlled for other variables that could impact the relationship between staffing levels, wage rates and hospitals' ALOS. These variables included whether each hospital was publicly or privately owned and whether the hospitals were either profit or not for profit. Additional variables controlled for included the year in which the data was collected, the percent of patient days in each hospital with a Medicare financial class, differences in each hospital's patient populations using each hospital's case mix index, each hospital's size using a staffed beds measure, each hospital's prior financial performance using prior year return on assets (ROA), and the total number of patient days for each hospital.

\section{Procedure}

A sample of 1,324 pooled cross sections from the previously described longitudinal unbalanced panel data sample of 352 California hospitals was used to test the hypotheses. We investigated the hypotheses using an ordinary least squares model, a least squares dummy variables model, and a random effects model.

The average size of the hospitals is 181 staffed beds ( $S D=138)$. Approximately $56 \%$ of the hospitals are private and non-profit, $26 \%$ of the hospitals are private and for profit, and $19 \%$ of the hospitals are publicly owned. The mean for the ALOS dependent measure is 5.87 (SD = 3.57 ). The mean for the ROA is $3.87 \%(S D=14.8)$. A correlation table is not presented as correlations among pooled variables are inappropriate and potentially misleading.

All variables were entered into the regression models simultaneously. Dummy variables representing each hospital were used in the LSDV analysis. In all other analyses, dummy variables for each of the longitudinal years of data were included to control for unobserved year effects. To better allow causality inferences, compensate for effect lags, and consider policy implications, the hypotheses were tested using a dependent variable at time $(\mathrm{t})$ one time period after the independent variables at time (t-1) (Cook \& Campbell, 1979; Huselid \& Becker, 1996; Kerlinger, 1986; Rogers \& Wright, 1999). A lag of one year has been used in previous research investigating the performance implications of compensation practices (Gerhart \& Milkovich, 1990). Having a time lag between our dependent and independent variables helps control for the potential that the causal relation might be reversed. For example, the lagged ROA measure controls for the possibility that, rather than hospitals who pay high wages having low ALOS, hospitals that have low ALOS are able to pay high wages due to the efficiency benefits associated with having low ALOS. 


\section{Results}

Table 1 presents the results of the three models investigating the hypotheses that hospitals' RN staffing practices and wage levels are negatively related to hospitals' ALOS.

All three models support the study's hypotheses. As shown in each model, greater RN hours were associated with lower (i.e. more efficient) ALOS levels. Similarly, greater wage levels are also associated with lower ALOS levels. While the magnitude of these effects varied somewhat across all three models, they were all at least significant at $p<0.01$. Thus, these results consistently show that increases in staffing levels and increases in wage levels are both associated with improved hospital efficiency, even after controlling for a wide array of organizational variables.

The significance of both staffing and wage effects lead to an immediate practical question: what provides a better return for a hospital: an increase in staffing, or an increase in wages? More specifically, if a hospital had the choice of increasing staffing levels by one full time equivalent (at a cost of 2080 hours at the current wage level), or increasing wages by the same amount (2080 hours times the current wage level divided by the total number of RN hours worked), which would yield the greatest ALOS benefit?

To try to answer this question, we used the results of all three models. Using the beta-values from Table 1, we first estimated ALOS for each hospital, but assuming that RN hours were increased by 2080. Second, we estimated the ALOS for each hospital, assuming that the RN wage level was increased by $(2080 *$ current wage level/total RN hours). Both estimates were intended to be a result of an equal increase in human resource costs. It should be noted that the estimates may not truly be equal, as we are relying on average staffing levels (we do not know overtime costs), and are not including the costs associated with payroll taxes, benefits, etc. Nonetheless, this monetary equivalent method provides a reasonable estimate of the relative value of increased staffing vs. increased wages.

The results of these estimates across all three models are somewhat inconsistent. The estimates for the LSDV and random effects models both suggest that, for most hospitals ( $96 \%$ and $93 \%$ respectively for the two models), increases in wages led to a greater improvement in ALOS than an increase by one RN. The OLS model, however, suggested that increased staffing had a more beneficial effect for all hospitals. 
Table 1. The Effects of Hospitals' RN Staffing Levels and Wage Practices on Hospitals' Average Lengths of Stay.

\begin{tabular}{|c|c|c|c|c|}
\hline \multirow{2}{*}{\multicolumn{2}{|c|}{$\begin{array}{c}\text { Independent Variables (at } t-1 \text { ) } \\
\text { Coefficient }\end{array}$}} & \multirow{2}{*}{$\frac{\text { OLS }}{\text { Coefficient }}$} & \multirow{2}{*}{$\frac{\text { LSDV }}{\text { Coefficient }}$} & \multirow{2}{*}{$\begin{array}{c}\begin{array}{c}\text { Random } \\
\text { Effects }\end{array} \\
\text { Coefficient }\end{array}$} \\
\hline & & & & \\
\hline \multirow[t]{7}{*}{$\begin{array}{l}\text { Organizational } \\
\text { Control Variables }\end{array}$} & Profit Status & $\begin{array}{l}-0.33 \\
(0.08)^{* * *}\end{array}$ & $\begin{array}{l}0.073 \\
(0.11)\end{array}$ & $\begin{array}{c}0.081 \\
(0.096)\end{array}$ \\
\hline & Ownership & $\begin{array}{l}-0.43 \\
(0.09)^{* * *}\end{array}$ & $\begin{array}{l}0.0005 \mathrm{I} \\
(0.10)\end{array}$ & $\begin{array}{l}-0.16 \\
(0.093)\end{array}$ \\
\hline & Size (Staffed Beds) & $\begin{array}{r}-0.000088 \\
(0.00078)\end{array}$ & $\begin{array}{c}0.00049 \\
(0.00065)\end{array}$ & $\begin{array}{r}0.00010 \\
(0.00062)\end{array}$ \\
\hline & In (Total Patient Days) & $\begin{array}{l}4.58 \\
(0.17)^{* * *}\end{array}$ & $\begin{array}{l}1.52 \\
(0.17)^{* * *}\end{array}$ & $\begin{array}{l}1.66 \\
(0.16)^{-\ldots * *}\end{array}$ \\
\hline & $\%$ Medicare Days & $\begin{array}{l}-5.03 \\
(0.43)^{* * *}\end{array}$ & $\begin{array}{l}-0.75 \\
(0.46)\end{array}$ & $\begin{array}{l}-1.29 \\
(0.43)^{* *}\end{array}$ \\
\hline & Case Mix & $\begin{array}{l}5.10 \\
(0.35)^{* * *}\end{array}$ & $\begin{array}{c}0.89 \\
(0.41)^{*}\end{array}$ & $\begin{array}{c}1.36 \\
(0.37)^{* * * *}\end{array}$ \\
\hline & ROA & $\begin{array}{c}-0.14 \\
(0.46)\end{array}$ & $\begin{array}{l}-0.46 \\
(0.23)^{*}\end{array}$ & $\begin{array}{l}-0.43 \\
(0.23)^{*}\end{array}$ \\
\hline \multirow[t]{5}{*}{$\begin{array}{l}\text { Independent } \\
\text { Variables }\end{array}$} & In (Total RN Hours) & $\begin{array}{l}-5.29 \\
(0.14)^{\cdots}\end{array}$ & $\begin{array}{l}-0.70 \\
(0.14)^{3 *}\end{array}$ & $\begin{array}{l}-1.40 \\
(0.13)^{\times \times \star}\end{array}$ \\
\hline & RN Wage Level & $\begin{array}{l}-0.059 \\
\left(0.017^{1 * *}\right.\end{array}$ & $\begin{array}{l}-0.046 \\
(0.015)^{* *}\end{array}$ & $\begin{array}{l}-0.071 \\
(0.014)^{* *+}\end{array}$ \\
\hline & Overall $\mathrm{R}$ squared & 0.61 & 0.98 & 0.97 \\
\hline & Adjusted R squared & 0.61 & 0.97 & 0.97 \\
\hline & F-value of model & $164.84^{*+*}$ & $119.60^{2+*}$ & $114.25^{2 * t}$ \\
\hline
\end{tabular}

Note: For each model, $\mathrm{N}=1262$. All models include dummy variables representing the year of data. The LSDV model also includes a dummy variable for each hospital. The effects associated with the firm and time variables are not shown. All data is derived from reports using July.June reporting periods except the case mix control variable which is a calendar year measure.

" $p<0.05$

${ }^{* *} p<0.01$

${ }^{* * \times} p<0.001$

\section{Discussion}

This research investigated the relation between hospitals' RN staffing levels, RN wage practices, and ALOS. Findings support the hypothesized relations that more RNs, and better paid RNs, will be associated with improved (i.e. lower) ALOS.

Efficiency wage theory, applied to a health care setting, suggests that high wages beneficially influences RN's efficiency, quality of care, and thus hospitals' ALOS. These findings, while consistent with those from other settings (e .g. Capelli \& Chauvin, 1991; Lazear, 1979; Raff \& Summers, 1987), represent a largely unexplored approach to understanding factors that may affect hospitals' ALOS. Specifically, the 
results show that a human resource practice (i.e. number of RNs and wage practices for RNs), relates to hospitals' performance (i.e. hospitals' ALOS). Thus, consistent with the tenets of strategic human resource management, this research strongly supports the view that the management of health care staff, through human resource practices, potentially affects hospitals' performance.

Our results also show the relative benefit of greater staffing versus greater compensation. Although our results are different for the OLS model in comparison to the LSDV and random effects models, we suggest that data support the view that compensation may play the larger role. The LSDV and random effects models are both more predictive than the OLS model in terms of F-tests and Rsquared values, and from a statistical perspective it has been proposed that LSDV and random effects models are superior to OLS models when analyzing pooled cross sections (Sayrs, 1989). While certainly more research is needed before definitive conclusions can be drawn, our results suggest that if considering the allocation of a limited set of resources, hospitals may be better served increasing RN pay than increasing RN staff.

For practice, these results suggest that hospitals' human resource practices likely influence the quality of care hospitals render. In particular, these results suggest the importance of considering RN compensation practices. Specifically, the results provide some support for RNs' arguments that hospitals' compensation practices do affect the standard of care. For healthcare managers, these results indicate that clinical consequences likely result from decisions related to RN compensation practices and that there are negative consequences associated with paying RNs below average wages (i.e. increased ALOS), and positive consequences from paying RNs above average wages (i.e. decreased ALOS). While cost increases clearly result from hiring more RNs and paying RNs greater wages, the efficiency benefits of lower ALOS should not be discounted. In particular, health care managers should investigate the cost dynamics of their specific institutions and assess the degree to which increased RN labor costs may be offset by the financial benefits associated with efficiency increases due to decreased ALOS.

Of course, caution must be used in inferring a causal relationship between hospitals' RN wage practices and hospitals' ALOS. Specifically, as this research is of a cross sectional nature lacking experimental design, the direction of causal relations and the influence of third variables remains unclear (Cook \& Campbell, 1979; Kerlinger, 1986). By using a dependent variable from one year later than the independent variables, our results are somewhat more suggestive of a causal relationship. Nonetheless, more in depth research is needed to truly understand the mechanisms through which staffing and compensation practices relate to hospital efficiency and patient care. 
In particular, our results do directly show how compensation practices are associated with greater efficiency. Our hypothesis is based on the precepts of efficiency theory, and indeed it is supported. However, we do not actually examine the effects of wages on recruiting levels, individual motivation, individual performance, etc. Our results at the hospital-level of analysis are useful, but individual-level analyses will help explain how pay leads to greater efficiency. For example, it is possible that greater pay leads to greater motivation; or, it is possible that pay is associated with greater RN experience, which is what leads to better ALOS. Our results do provide some useful information for health care management practice, but they also generate a host of new questions meriting further research.

Future research should also continue to investigate the effect of other compensation and human resource management practices on hospitals' ALOS. For example, what are the effects of merit pay, bonuses, etc? How does training enhance ALOS? What sort of hiring practices improve efficiency? It would also be valuable to examine other positions in the hospitals. One potential area of investigating is a consideration of hospitals' human resource practices and their effects on employee physicians. Traditionally, physicians have been self-employed practitioners. However, recent trends in the healthcare industry have led to some physicians (e.g. hospitalists) becoming hospital employees. In these cases, consideration of human resource management practices' effects on hospitals' ALOS may be particularly relevant. Another interesting area of research might be to investigate the effects of human resource management practices in specific clinical areas on performance measures relevant to these areas. For instance, research could investigate the effect of human resource management practices (e.g. incentive compensation, etc.) designed to improve specific types of care or outcomes (e.g. ALOS for particular diagnosis related groupings) in particular clinical areas.

\section{Conclusion}

This study indicates that the number of nurses on staff, and the pay of those nurses, is significantly related to hospitals' ALOS. Furthermore, our findings suggest that pay may have a greater influence on ALOS than staffing. Our findings are both theoretically and practically important, and future research should continue to explore the link between hospitals' human resource practices and their operational performance. 


\section{References}

Adams, J. S. (1963). Toward an understanding of inequity. Journal of Abnormal and Social Psychology, $67,422-436$.

Aiken, L.A.. Clarke, S.P., Sloane, D.M., Sochalski, J.A. et al. (2001). Nurses' reports of hospital quality of care and working conditions in five countries. Health Affairs, 20. 43-53.

Akerlof, G. A. (1982). Labor contracts as partial gift exchange. The Quarterly Journal of Economics, 97,543-569.

Akerlof, G. A., \& Yellen, J. L. (1984). Efficiency Wage Models of the Labor Market. Cambridge: Cambridge University Press.

American Hospital Association (1993). AHA Hospital Statistics (1992-1993 ed.). Chicago: American Hospital Association.

Becker, B. E., \& Huselid, M.A. (1998). High performance work systems and firm performance: A synthesis of research and managerial implications. Research in Personnel and Human Resources Management, 16, 53-101.

Boudreua, J. W., \& Rynes, S. L. (1985). The role of recruitment in staffing utility analysis. Journal of Applied Psychology, 70, 354-366.

Campbell, C. M., III. (1993). Do firms pay efficiency wages? Evidence with data the firm level. Journal of Labor Economics, 11, 442-470.

Cappelli, P., \& Chauvin, K. (1991). An interplant test of the efficiency wage hypothesis. The Quarterly Journal of Economics, 106, 769-787.

Carey, K. (2000). Hospital cost containment and length of stay: An econometric analysis. Southern Economic Journal, 67, 414-426.

Cook, T. D., \& Campbell, D. T. (1979). Quasi-Experimentation: Design and Analysis for Field Settings. Boston: Houghton Mifflin Company.

Cropanzano, R., \& Greenberg, J. (1997). Progress in organizational justice: Tunneling through the maze. In: C. L. Cooper \& I. T. Robertson (Eds), International Review of Industrial and Organizational Psychology: 1997. New York: John Wiley \& Sons.

Festinger, L. A. (1954). A theory of social comparison processes. Human Relations, 7, 117-140.

Gerhart, B., \& Milkovich, G. T. (1990). Organizational differences in managerial compensation and financial performance. Academy of Management Journal, 33, 663-691. 
Gerhart, B., \& Milkovich, G. T. (1992). Employee compensation: Research and practice. In: M. D. Dunnette (Ed.), Handbook of Industrial and Organizational Psychology, (Vol. 3, pp. 481-569). Palo Alto, CA: Consulting Psychologists Press.

Hunter, J. E., \& Hunter, R.F. (1984). Validity and alternative predictors of job performance. Psychological Bulletin, 96, 72-98.

Kerlinger, F. N. (1986). Foundations of Behavioral Research (3rd ed.). Fort Worth: Harcourt Brace College Publishers.

Langland-Orban, B., Gapenski, L. C., \& Vogel, W. B. (1996). Differences in characteristics of hospitals with sustained high and sustained low profitability. Hospital and Health Services Administration, 41, 385-405.

Lazear, E. P. (1979). Why is there mandatory retirement. Journal of Political Economy, 87, 1261-1284.

MacEachern, M. T. (1962). Hospital Organization and Management (3rd ed.). Berwyn: Physicians' Record Company.

Melberg, S. E. (1997). Effects of changing skill mix. Nursing Management, 28, 47-48.

Milkovich, G. T., \& Newman, J. M. (2002). Compensation. Chicago: Irwin.

Needleman, J., Buerhaus, P., Mattke, S., Stewart, M., \& Zelevinsky, K. (2001). Nurse Staffing and Patient Outcomes in Hospitals. Boston: Harvard School of Public Health: Final Report for the Health Resources and Services Administration under contract 230-99-0021.

OSHPD (1991). Accounting and Reporting Manual for California Hospitals. Sacramento: Office of Statewide Health Planning and Development.

Phillips, J. F. (1999). Do managerial efficiency and social responsibility drive long-term financial performance of not-for-profit hospitals before acquisition? Journal of Health Care Finance, 25, 67-76.

Raff, D. M. G., \& Summers, L. H. (1987). Did henry ford pay efficiency wages? Journal of Labor Economics, 5, S57-S86.

Rebitzer, J. B., \& Taylor, L. J. (1995). Efficiency wages and employment rents: The employer size wage effect in the job market for lawyers. Journal of Labor Economics, 13, 678-707.

Robertson, R. H., Dowd, S. B., \& Hassan, M. (1997). Skill-specific staffing intensity and the cost of hospital care. Health Care Management Review, 22, 61-71.

Rogers, E.W. \& Wright, P. W. (1999). Measuring organizational performance in strategic human resource management: Looking beyond the lamp post. Center for Advanced Human Resource Studies (Working Paper No. 98-24). 
Sayrs, L. W. (1989). Pooled time series analysis. In: M. S. Lewis-Beck (Ed.). Quantitative Applications in the Social Sciences (Number 70). Sage Publications.

Sear, A. M. (1992). Operating characteristics and comparative performance of investor owned multihospital systems. Hospital and Health Services Administration, 37, 403-416.

SEIU (2002). The Service Employees International Union Nurse Alliance World Wide Web Site (15 April). www.nursealliance.org: The Service Employees International Union.

Thomas, J. W. (1996). Does risk adjusted readmission rate provide valid information on hospital quality? Inquiry, 33, 258-270.

Thomas, J. W., Guire, K. E., \& Horvat, G. G. (1997). Is patient length of stay related to quality of care? Hospital and Health Services Administration, 42, 489-505.

Thomas, J. W., \& Hofer, T. P. (1998). Research evidence on the validity of risk-adjusted mortality rate as a measure of hospital quality of care, Medical Care Research and Review, 55, 371-404.

Thomas, J. W., \& Hofer, T. P. (1999). Accuracy of risk-adjusted mortality rate as a measure of hospital quality and care. Medical Care, 37, 83-92.

Walsh, F. (1999). A multiscetor model of efficiency wages. Journal of Labor Economics, 17, 351-376.

Weiss, A. (1980). Job queues and layoffs in labor markets with flexible wages. Journal of Political Economy. 88, 526-538.

Williams, M. L., \& Dreher, G. F. (1992). Compensation system attributes and applicant pool characteristics. Academy of Management Journal, 35, 571-595.

Yellen, J. L. (1984). Efficiency wage models of unemployment. American Economic Review, 74, 200-205. 